دراسة مرضية نسجية وقياسية شكلية لتأثير مركب الستانوزولول على كبد ذكور الجرذان

\author{
عمار غانم الحائك \\ كلية الطب البيطري

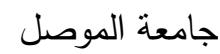

alhaaik_ag@uomosul.edu.iq

\author{
انتصار رحيم الكناني \\ كلية طب الأسنان \\ الجامعة العراقية
}

\author{
محمد يونس احمد ال فتحي \\ قسم علوم الحياة/ كلية التربية للعلوم الصرفة \\ جامعة الموصل
}

(أستلم 2019/5/13 ؛ قُبل 2019/6/18)

\begin{abstract}
الملخص
هدفت الدراسة لـعرفة التأثيرات المرضية النسجية والثكلية القياسية لمركب الستانوزولول وعلى فترات مختلفة على كبد ذكور الجرذان. تضمنت الدراسة 80 من ذكور الجرذان البيض قسمت عشوائياً إلى أربعة مجاميع بواقع 20 جرذاً لكل مجموعة، وشملت فئل

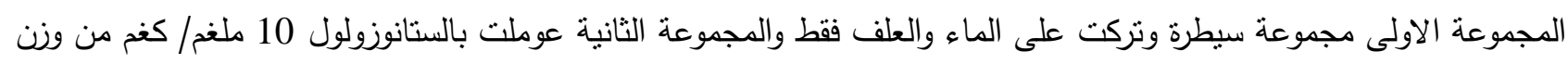

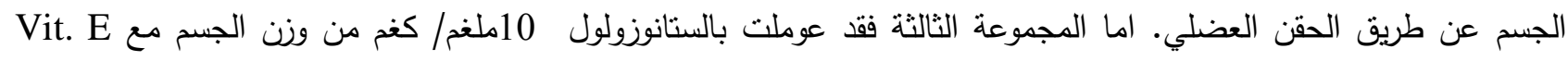

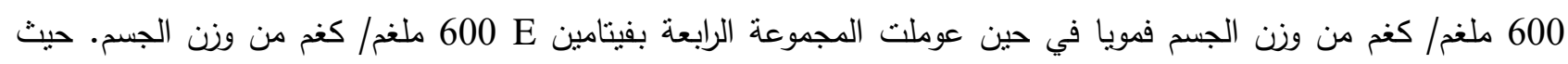

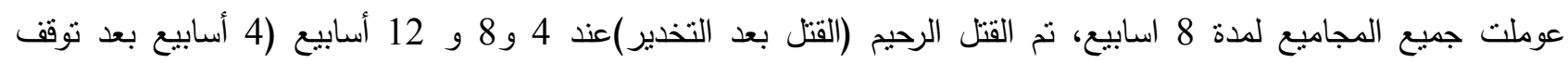
المعاملة) وأخذت نماذج من الكبد بواقع ثمان عينات من كل مجموعة. أظهرت المقاطع النسجية للكبد في المجموعة الثانية وجود تغيرات مرضية نسجية تمنلت بالتتكس الفجوي والدهني في هيولي الخلايا الكبدية مع توسع الجيبانيات واحتقانها وبعد ثمانية اسابيع

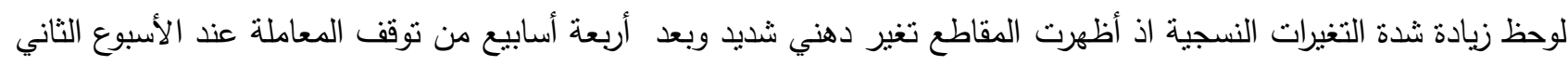

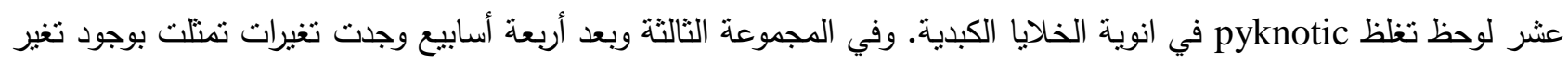
دهني منتشر وتوسع الجيبانيات وبعد ثمان أسابيع من المعاملة لوحظ توسع الجيبانيات مع تضخم خلايا كوفر .

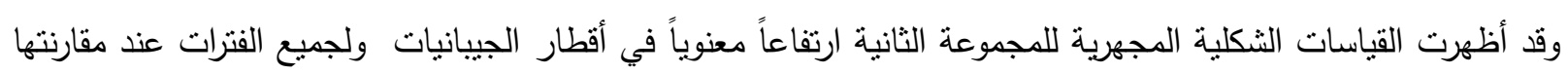

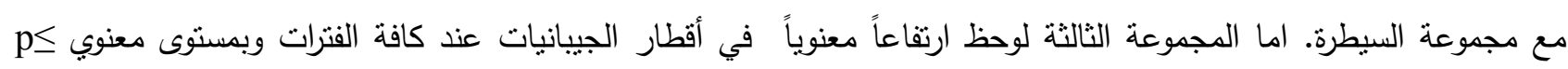
0.05 مقارنة مع جرذان مجموعة السيطرة، اما عند مقارنتها مع جرذان المجموعة الثانبة فقد أظهرت انخفاضاً معنوياً في أقطار كارئ

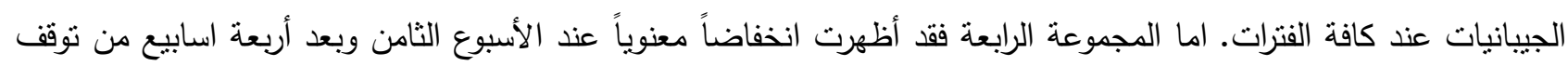
المعاملة ( الأسبوع الثاني عشر) عند اغلب الفترات مقارنة مع مجموعة السيطرة. بينما أوضحت نتائج القياسات المجهرية للمجموعة الثانية وجود انخفاض معنوي في أقطار انوية الخلايا الكبدية عند مستوى معنوي 0.05 > ولجميع الفترات عند مقارنتها مع مجموعة السيطرة. وبينت المجموعة الثالثة وجود ارتفاع غير معنوي في أقطار انوية الخلايا الكبدية عند كافة الفترات مقارنة مع جرذان المجموعة المعاملة بالستانوزولول بالتركيز 10 ملغم/كغم من وزن الجسم.

الكلمات الدالة: المرضية النسجية، الثكلية القياسية، ستانوزولول، الكبد.
\end{abstract}


محمد يونس احمد ال فتحي واخرون

\section{Histopathological and Micromorphometrical Study for the Effect of Stanozolol on Liver of Male Rats}

\begin{tabular}{|c|c|c|}
\hline Mohamed Y. Al-Fathi & Entesar R. Al-Kennany & Ammar G. Al-Haaik \\
\hline Department of Biology & College of Dentistry & College of Veterinary Medicine \\
\hline College of Education for Pure Science & Al_Iraqia University & University of Mosul \\
\hline University of Mosul & & \\
\hline
\end{tabular}

ABSTRACT

The study aimed to investigate the histopathological and micromorphometric measurements of the effects of stanozolol with different concentrations and periods on the liver in male rats. The study included 80 male white rats divided randomly into four groups of 20 rats per group. The first included (control group) which get water and feed only. The second group was treated with stanozolol $10 \mathrm{mg} / \mathrm{kg}$. The third group was treated with stanozolol $10 \mathrm{mg} / \mathrm{kg}$ body weight with Vit. E $600 \mathrm{mg} / \mathrm{kg}$ body weight and the fourth group was treated with vitamin E $600 \mathrm{mg} / \mathrm{kg}$ body weight only. All groups were treated for 8 weeks. Euthanasia was performed at 4, 8 and 12 weeks (4 weeks after cessation of treatment) and liver samples were taken by eight samples and for all groups. The histological sections of the liver in the second group showed presence of histopathological changes represented by fatty degeneration of hepatic cells with the expansion and congestion of sinusoid. Eight weeks later, the intensity of histopathological changes were increased, the sections showed severe fatty change. Four weeks after the treatment cessation at the 12th week, pyknosis of the nuclei of the hepatic cells were observed. In the third group, the changes after four weeksrepre sented by diffuse fatty change and sinusoidal expansion. After eight weeks of treatment, sinusoidal expansion with hypertrophy of kupffer cells were observed.

The micromorphometric measurements of the second group on the sinusoidal diameters showed a significant increase at $\mathrm{p} \leq 0.05$ for all periods when compared with control group. The third group showed a significant increase at all periods and at a significant level $p \leq 0.05$ compared with control group, while it showed a significant decrease in the diameter of sinusoid at all periods and at a significant level $\mathrm{p} \leq 0.05$ compared with the rats of the second group. The fourth group showed a significant decrease at the eighth week and four weeks after cessation of treatment (week 12) at most periods. The results of the micromorphometric measurements of the second group showed a significant decrease in the diameter of hepatic cell nuclei at a significant level $\mathrm{p}$ $\leq 0.05$ and for all periods when compared with control group. The third group showed an insignificant increase in hepatic cell nuclei diameter at all periods compared with the treated group of $10-\mathrm{mg} / \mathrm{kg}$ body weight.

Keyword: histopathological, morphometric, stanozolol, liver.

\section{المقدمة}

تستخدم الستيرويدآت الاندروجينية الابتتائية Anabolic Androgenic Steroid ) من قبل الرياضيين

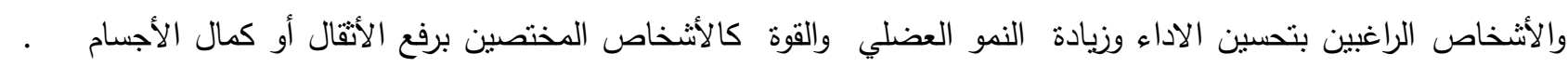
and Thieme, 2010) Buttner( الستيرويدية وهي مركبات صناعية لها وظائف مماتلة لهرمون التشتوستيرون (Vieira et al., 2019) وهناك العديد من التأثيرات

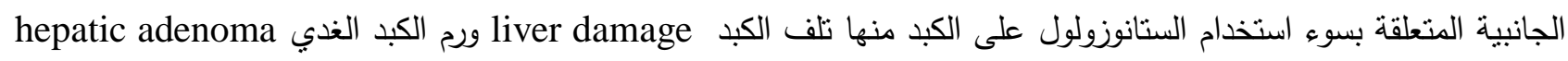
وسرطان الخلايا الكبدية hepatocellular carcinoma ومن المكن ان يسبب تتكساً في الخلايا الكبدية وتغيرات تتكسيه في ونيات الماينوكوندريا (لذا جاءت هذه الدراسة للتعرف على التأثيرات Vorona, 2015 and Nieschlag (Balcells et al., 2017 
المرضية الناجمة عن إعطاء stanozolol لذكور الجرذان البالغة من خلال التغيرات المرضية النسجية في الكبد و معرفة ان

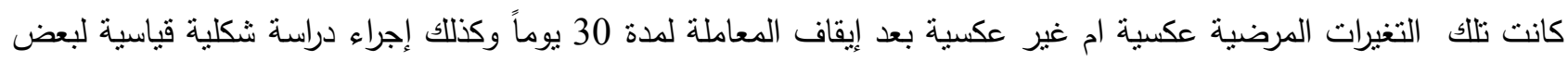

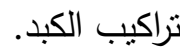

\section{المواد وطرائق العمل}

استخدمت في هذه الدراسة 80 من ذكور الجرذان البيض Albino male rats بعمر يتراوح 2-3 شهور وبوزن يتراوح بين 125-200 غم تم تربيتها في أقفاص بلاستيكية في غرفة بدرجة حرارة (22-28) درجة مئوية مع مدة إضاءة وتهوية 10

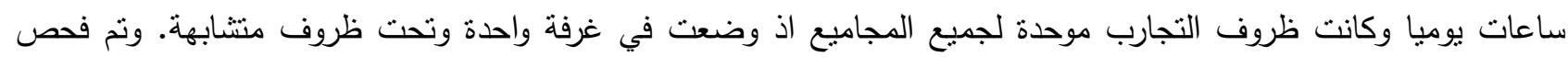

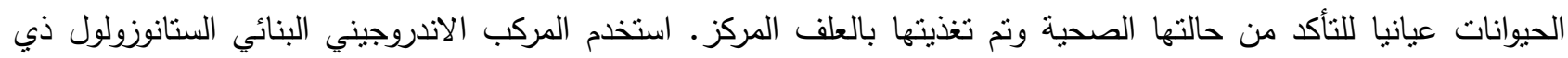
الاسم التجاري Venaject بشكل محلول والمصنع من قبل شركة Thaiger pharma/ Thailand وبتركيز 50 ملغرام/ مليلتر

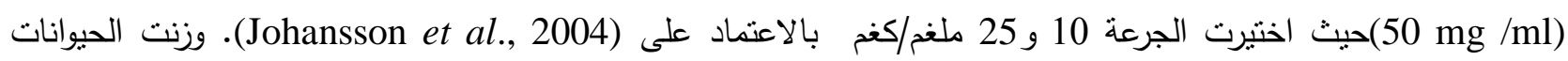
E أسبوعيا لتحديد الجرعة حيث يتم تحضير الجرع وحسب المجاميع التي ستنكر في تصميم التجربة. كما نم استخدام فيتأمين المنتج من قبل شركة premier health products ltd. UK وبتركيز 286 ملغم وتم تحديد الجرعة وفقا لوزن الحيوان .(Jassim and Hassan, 2011) حيث تم إعطاء الجرعة بمقدار 600 ملغم لكل كيلو غرام من وزن الجسم

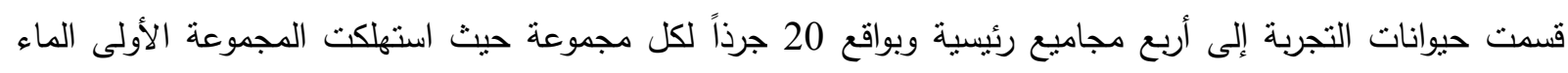
والعلف وعدت مجموعة سيطرة في حين أعطيث المجموعة الثانية ستانوزولول 10 ملغم/ كغم من وزن الجسم عن طريق الحقن

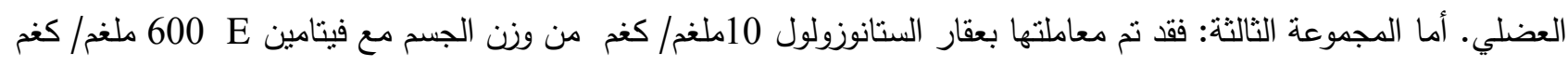
من وزن الجسم عن طريق التجريع بالفم. اما المجموعة الرابعة فقد عوملت بفيتامين E 600 ملغم/ كغم من وزن الجسم فمويا.

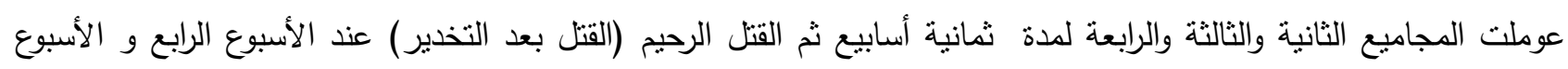

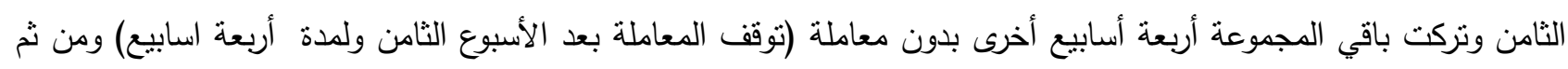

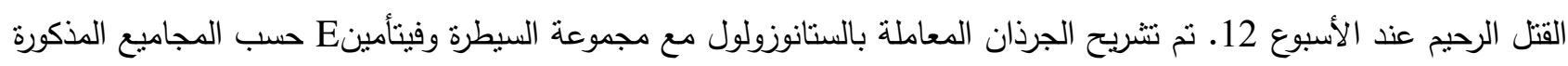

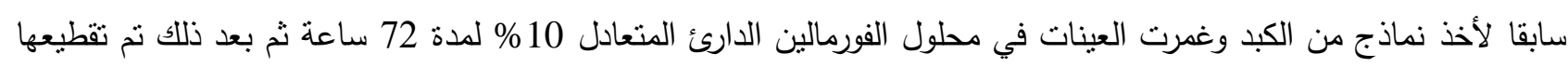

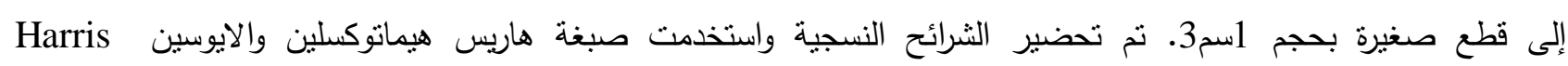

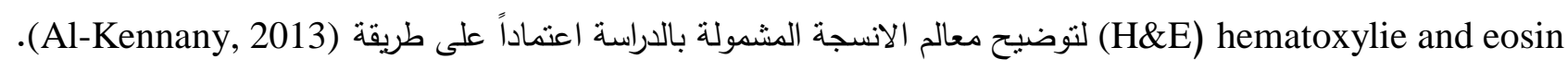
صورت المقاطع النسجية باستخدام كاميرا رقمية مجهرية نوع USB 2.0 digital image camera. China مزودة ببرنامج تحليل الصور Scope Image 9.0 . تم اجراء التحليل الاحصائي للبيانات الخاصة بهذه الدراسة بواسطة اختبار تحليل التباين واستخدم اختبار دنكن Dune way analysis of variance (ANOVA) Iالخطأ القياسي)، وقد استخدم برنامج التحليل الاحصائي SPSS في تحليل جميع البيانات وكان مستوى الاختلاف لجميع

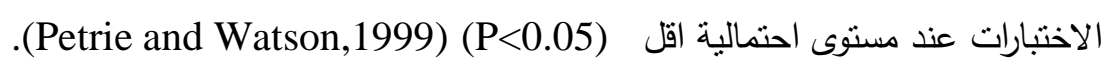
النتائج

التغيرات المرضية النسجية

لم يلحظ وجود آفات مرضية نسجية في كبد جرذان مجموعة السيطرة (الثنكل 1). في حين تمنلت الآفات النسجية لكبد

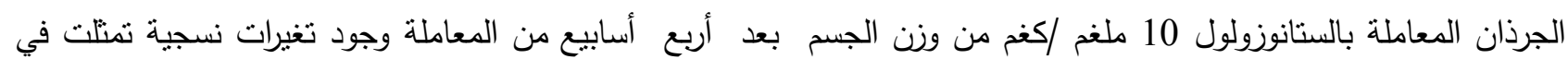

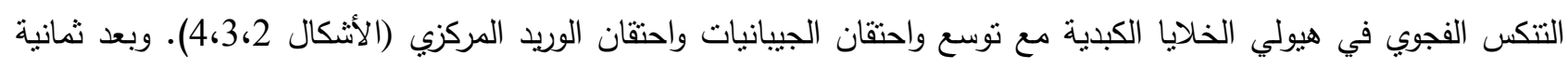
أسابيع من المعاملة لوحظ زيادة شدة التغيرات النسجية إذ أظهرت المقاطع وجود تغير دهني شديد (الثكل 5) وبعد أربع أسابيع

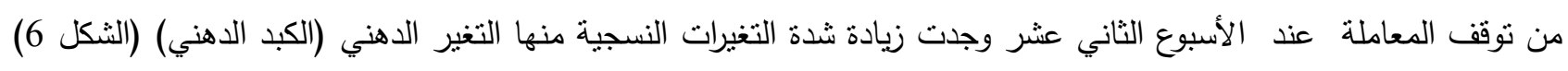


مع توسع الجيبانيات واحتقانها فضلا عن تغلظ pyknotic انوية الخلايا الكبدية (الثكل 7). بينما اظهرت المقاطع النسجية لكبد

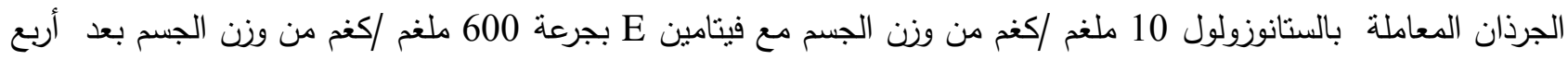
اسابيع وجود تغيرات تمتلت بوجود تغير دهني منتشر وتوسع الجيبانيات كذللك ظهر تحلل انوية الخلايا الكبدية وتضخم الخلايا (الثكلان 8 ، 9) وبعد ثمانية أسابيع من المعاملة لوحظ توسع الجيبانيات مع تضخم خلايا كوفر (الثكل

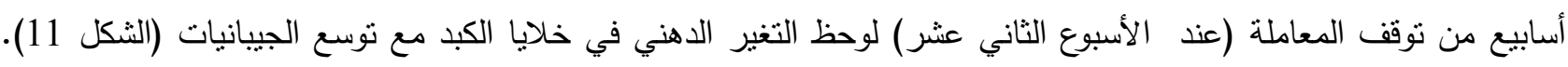
وفي المجموعة المعاملة بفيتامين E بجرعة 600 ملغم /كغم من وزن الجسم لم يلحظ وجود تغيرات مرضية نسجية ولكافة الفترات.

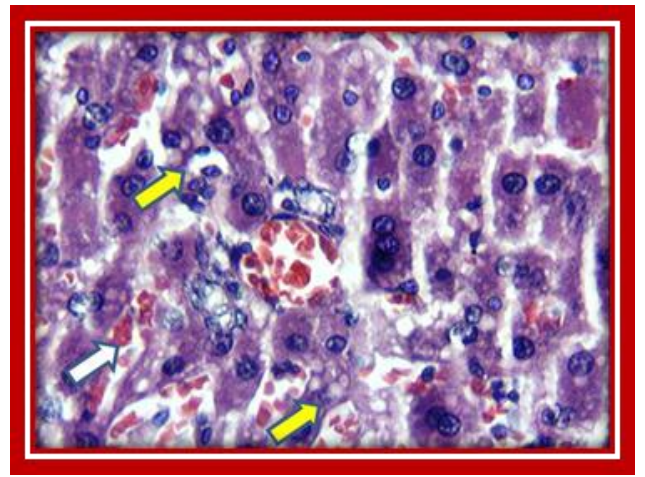

الثكل 2: مقطع نسجي لكبد جرذ معامل بالستانوزولول 10

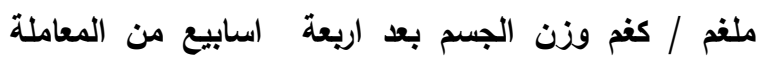

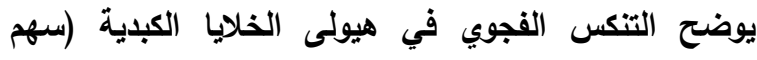

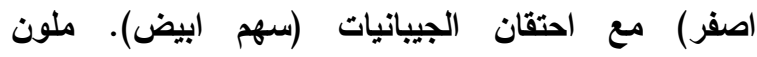
400X: هيماتوكسيلين ايوسين H\&E

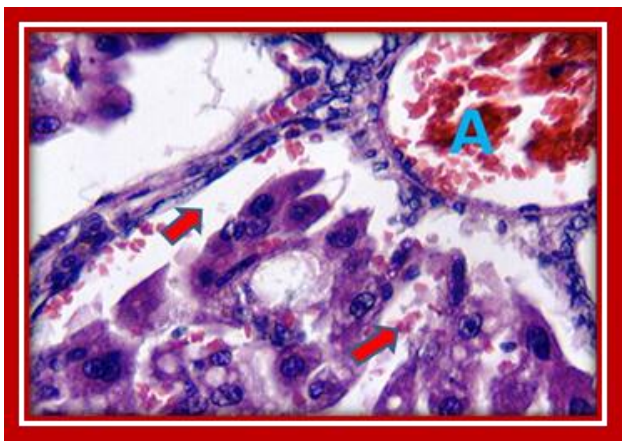

الثـــل 4 : مقطـــع نسـجي لكبـــ جـرذ معامـل بالستانوزولول 10 ملغم / كفم من وزن الجسم بعد

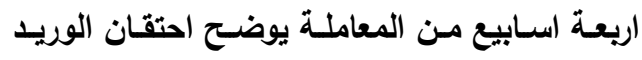
المركزي (A) مي توسيع الجيبانيات (سـهم احمر).

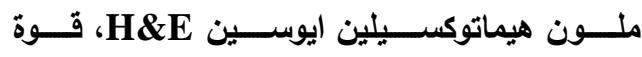
التكبير : 400X

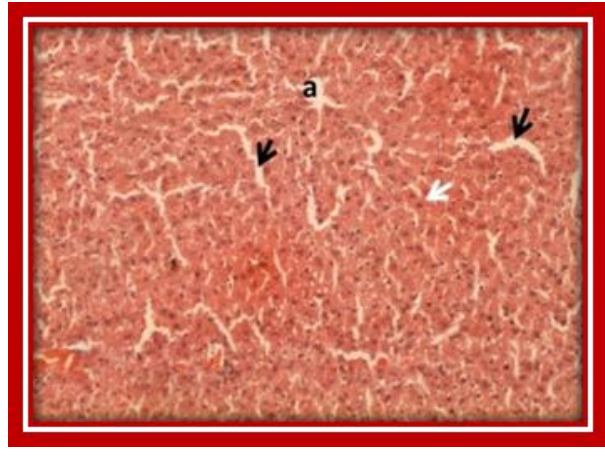

الثكل 1: مقطع نسجي لكبد جرذ يوضح التركيب السوي، الوريد المركزي (a)، الجيبانيات (سهم اسود) والخلايا

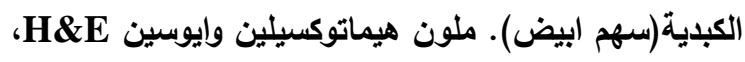
قوة التكبير: 400

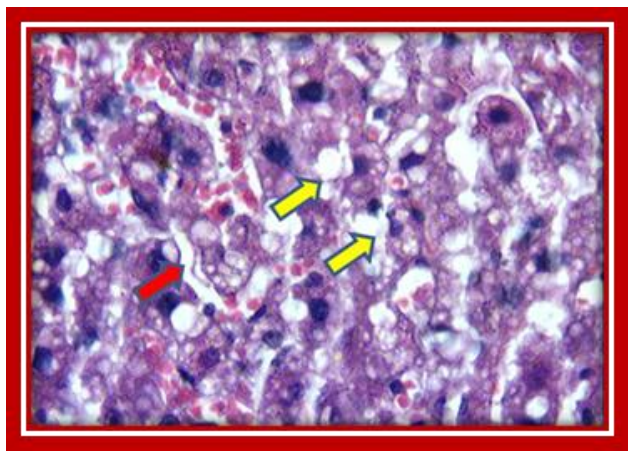

الثكل 3: مقطع نسجي لكبا جرذ معامل بالستانوزولول 10 ملغم / كفم من وزن الجسم بعد اريعة اسابيع من المعاملة يوضح التنكس الفجوي في

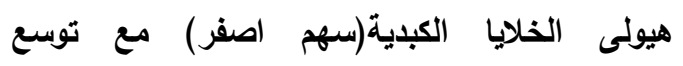
الجيبانيات واحتقانها (سهم احمر). ملون هيماتوكسيلين ايوسين H\&E) قوة التكبير:400X
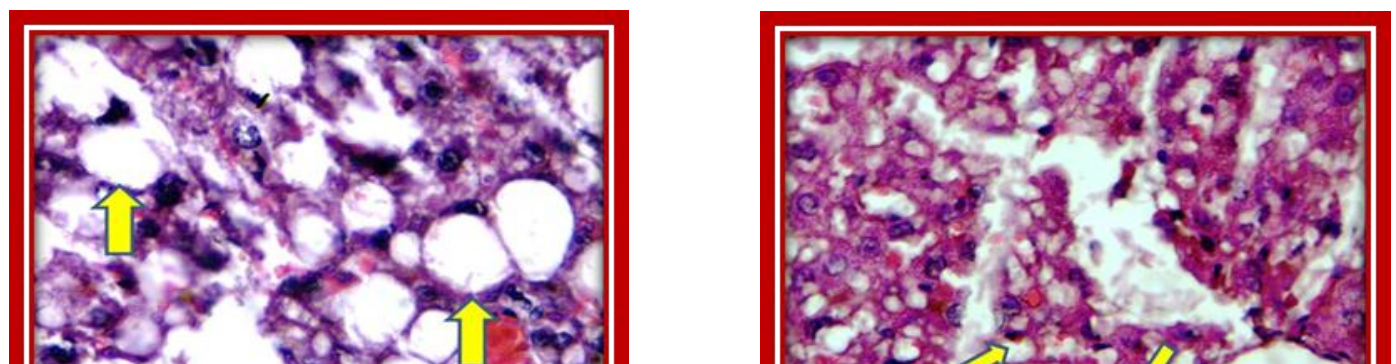
الثـــكل 6: مقطـــع نســـي لكبــــ جــرذ معامــل بالسـتانوزولول 10 ملغم / كغم مسن وزن الجسـم بعد اريعة اسابيع من توقف المعاملة يوضـح التغير الاهني(الكبد الـدهني) في هيـلي الخلايـا الكبديـة (ســـم). ملــون هيماتوكسـيلين ايوسـينين ، قــوة التكبير:A100X, B1000X

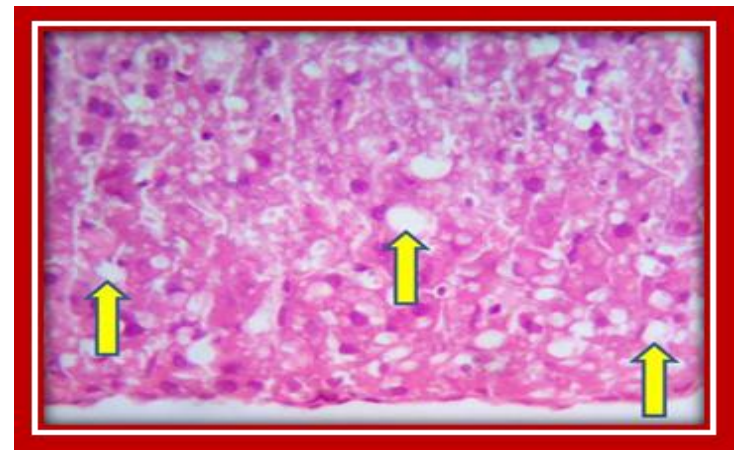

الثكل 8: مقطع نسجي لكبا جرذ معامل بالستانوزولول 600 E 10ملفم / كفم من وزن الجسم مع فيتأمين ملفم/كفم من وزن الجسم بعد اربعة اسابيع من المعاملة يوضح وجود التغير الدهني المنتشر في هيولى الخلايا الكباية (سهم اصفر). ملون هيماتوكسيلين ايوسين، قوة التكبيز:400X

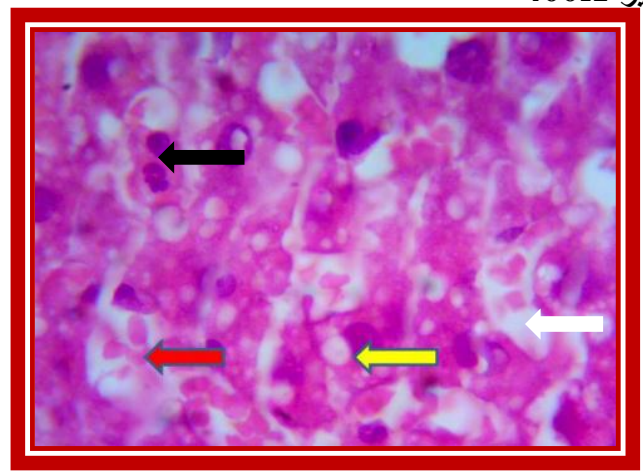

الشكل 10 : مقطع نسجي لكبا جرذ معامل بالستانوزولول

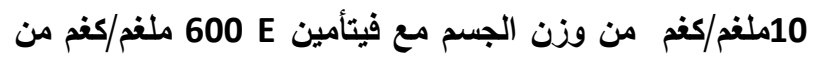
وزن الجسم بعد ثمانية اسابيع من المعاملة يوضع توسع الجيبانيات (سهم ابيض) مع تضخم خلايا كوفر (سهم احم)

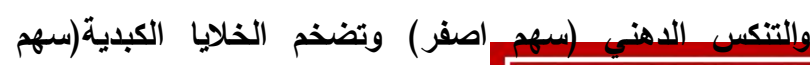
ين ايوسين، قوة التكبير :400X
الشكل 5: مفطع نسجي لكبا جرذ بالستانوزولول 10

ملفم/ كغم من وزن الجسم بعد ثمانية اسابيع من المعاملة يوضح التغير الدهي الثديا (الكبا الدهني)

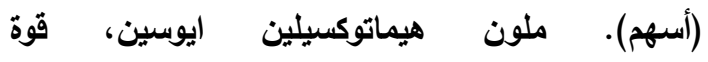
400X:التكبيز

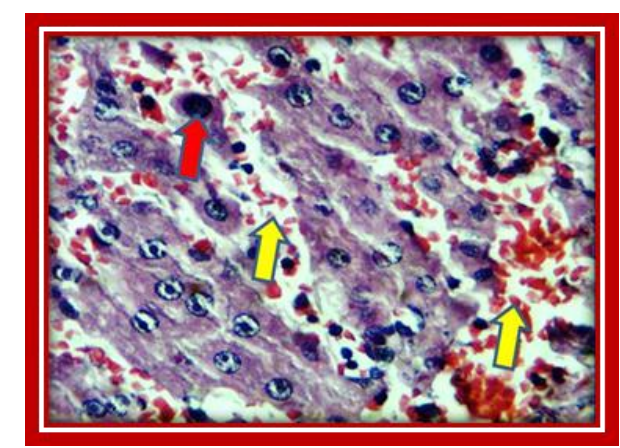

الثكل 7: مقطع نسجي لكبا جرذ معامل بالستانوزولول 10 ملغم / كغم من وزن الجسم بعد اريعة اسابيع من توقف المعاملة يوضح توسع واحتقان الاوعية الدموية (سهم اصفر) وتغلظ انوية الخلايا الكباية (سهم احمر) ملون هيماتوكسيلين ايوسين، قوة التكبير :

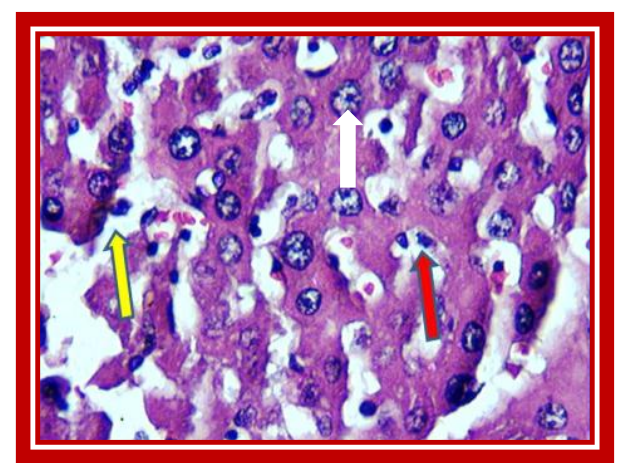

الشكل 9: صورة مكبرة لمقطع نسجي لكبا جرذ معامل معامل 600 E بالستانوزولول 10ملغم / كغم من وزن الجسم مع فيتأمين ملغم/كفم من وزن الجسم بعد أربعة اسابيع من المعاملة يوضع توسيع الجيبانيات (سهم احمر) مع التغير الدهني الثديد في هيولى الخلايا الكبدية(سهم اصفر) وتضخم الخلايا الكبدية (سهم اليض).ـملون هيماتوكسيلين ايوسين، قوة التكبير:400X 
الثكل111: مقطع نسجي لكبد جرذ معامل بالستانوزولول 10ملفم / كفم من وزن الجسم مع فيتأمين

600 E

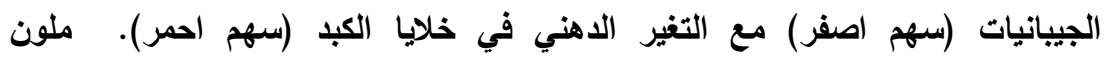

400X هيماتوكسيلين ايوسين ، قوة التكبير

نتائج القياسات المجهرية اقطار الجيبانيات

وضح (الجدول 1) نتائج القياسات المجرية لذكور الجرذان المعاملة بالستانوزولول بالتركيز 10 ملغم/كغم من وزن الجسم

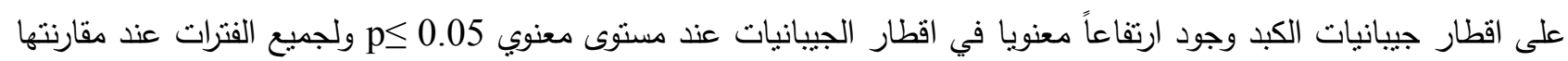

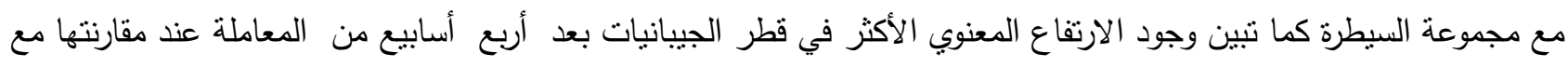

بقية الفترات بقيمة 8.3.0.3.

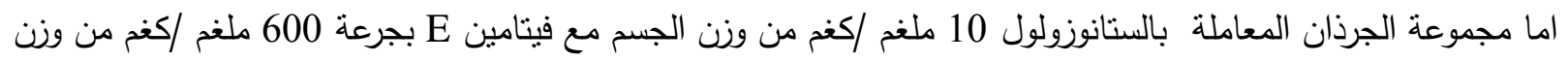

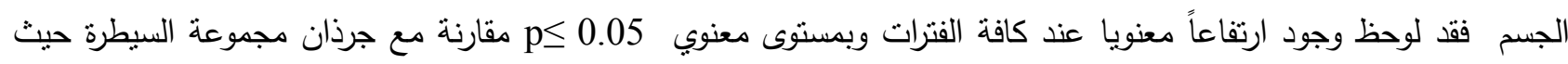

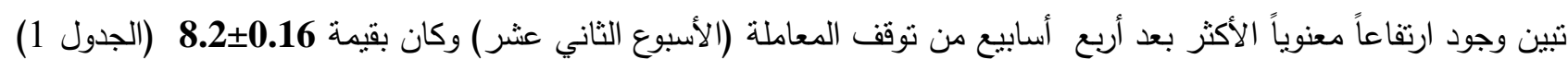

كما اظهرت المجموعة المعاملة بالستانوزولول 10 ملغم/ كغم من وزن الجسم مع فيتامين E بتركيز 600ملغم/كغم من

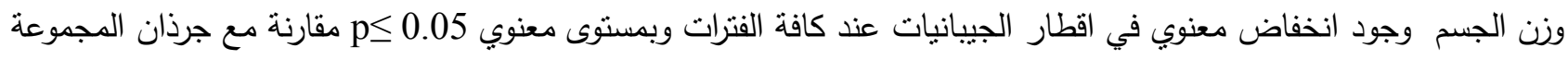
المعاملة بالستانوزولول بالتركيز 10 ملغم/كغم من وزن الجسم حيث كان اقل انخفاض بعد أربع اسابيع من المعاملة وكان بقيمة

5.48 $\mathbf{5 . 0 . 1}$

اما مجموعة الجرذان المعاملة بفيتامين E بتركيز 600 ملغم /كغم من وزن الجسم فقد أظهرت انخفاض معنويا عند الأسبوع الثامن وبعد أربع اسابيع من توقف المعاملة (الأسبوع الثاني عشر) وغير معنوي عند الأسبوع الرابع من المعاملة عند مستوى معنوي p p p مقارنة مع مجموعة السيطرة.

الجدول 1: يوضح تاثير فيتامين E بتركيز 600 ملغم /كغم من وزن الجسم في ذكور الجرذان المعاملة بالستانوزولول

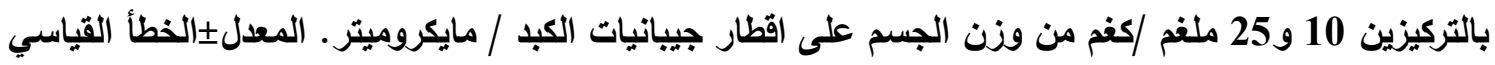


القيمة تمثل المعدل 土 الخطأ القياسي (24جرذ/ مجموعة)

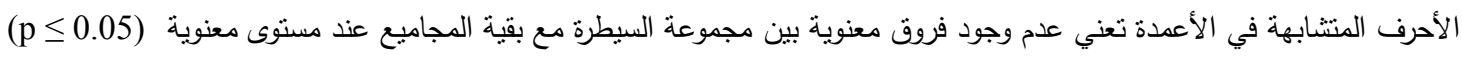

\begin{tabular}{|c|c|c|c|c|}
\hline $12 w$ & $8 w$ & $4 w$ & المعاملات & المجموعة \\
\hline $5.9 \pm 0.13$ a & $5.5 \pm 0.13 \mathrm{a}$ & $4.8 \pm 0.13 a$ & السيطرة & المجموعة الاولى \\
\hline $8.3 \pm 0.3 \mathrm{~b}$ & $6.64 \pm 0.16 b$ & $5.64 \pm 0.16 \mathrm{~b}$ & ستانوزولول 10ملغم/كغ & المجموعة الثانية \\
\hline $8.2 \pm 0.16 b$ & $6.62 \pm 0.2 \mathrm{~b}$ & $5.48 \pm 0.1 \mathrm{~b}$ & ستانوزولول 10ملغم/كغم مع 600 ملغم/كغمE & المجموعة الثالثة \\
\hline $4.64 \pm 0.18 b$ & $4.04 \pm 0.7 \mathrm{~b}$ & $4.6 \pm 0.2 \mathrm{a}$ & فيتامين 600ملغم/كغمE & المجموعة الرابعة \\
\hline
\end{tabular}

الأحرف المختلفة في الأعمدة تعني وجود فروق معنوية مجموعة السيطرة مع بقية المجاميع عند مستوى معنوية (p 0.05$)$

اقطار انوية الخلايا الكبدية يوضح (الجدول 2) نتائج القياسات المجهية لذكور الجرذان المعاملة بالستانوزولول بالتركيز 10 ملغم/كغم من وزن الجسم

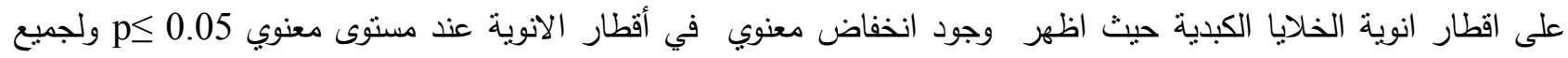

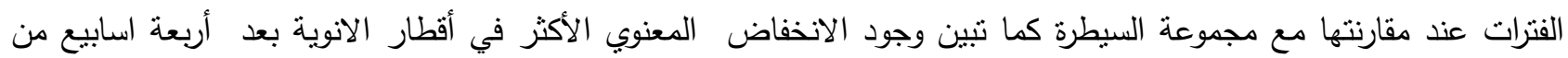

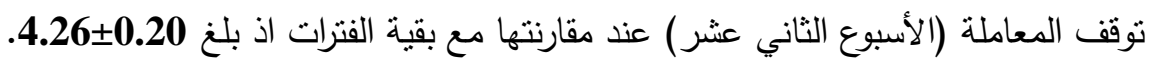

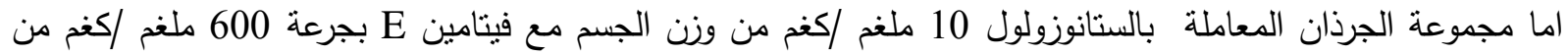

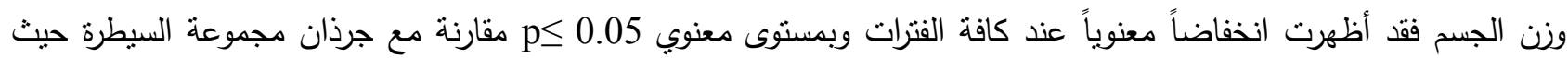

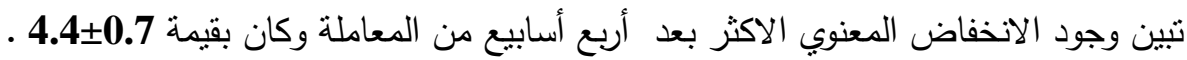
بينت المجموعة المعاملة بالستانوزولول 10 ملغم/ كغم من وزن الجسم مع فيتامين E بتركيز 600ملغم/كغم من وزن الجسم

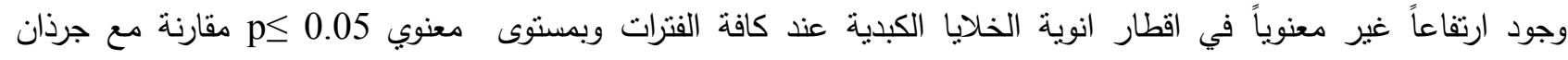

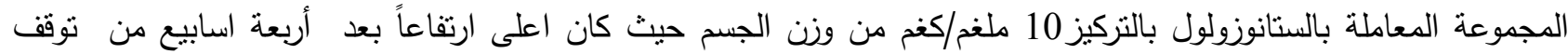

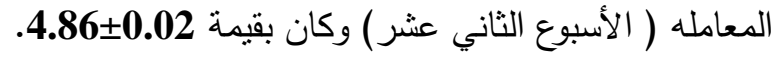
اما مجموعة الجرذان المعاملة بفيتامين E بتركيز 600 ملغم /كغم من وزن الجسم فقد اظهرت ارتفاعاً معنويا عند كافة

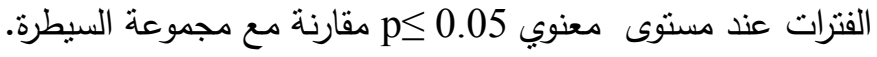

الجدول 2: يوضح تاثير فيتامين E بتركيز 600 ملفم /كفم من وزن الجسم في ذكور الجرذان المعاملة بالستانوزولول

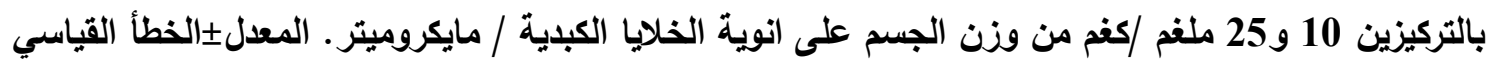




\begin{tabular}{|c|c|c|c|c|}
\hline $12 w$ & $8 w$ & $4 w$ & المعاملات & المجموعة \\
\hline $.4 \pm 0.13 \mathrm{a} 5$ & $5.3 \pm 0.13 \mathrm{a}$ & $.1 \pm 0.13$ a5 & السيطرة & المجموعة الاولى \\
\hline $4.26 \pm 0.20 \mathrm{~b}$ & $4.5 \pm 0.15 \mathrm{~b}$ & $4.34 \pm 0.4 \mathrm{~b}$ & ستانوزولول 10ملغم/كغ & المجموعة الثانية \\
\hline $6 \pm 0.02 \mathrm{b84}$ & $4.62 \pm 0.19 \mathrm{~b}$ & $4.4 \pm 0.7 \mathrm{~b}$ & 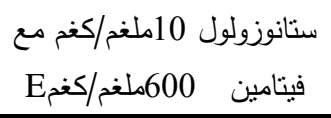 & المجموعة الثالثة \\
\hline $5.54 \pm 0.09 a$ & $5.44 \pm 0.16 \mathrm{a}$ & $5.32 \pm 0.1 \mathrm{a}$ & فينامين 600ملغم/كغغ & المجموعة الزابعة \\
\hline
\end{tabular}

القيمة تمثل المعدل 土 الخطأ القياسي (24جرذ/ مجموعة)

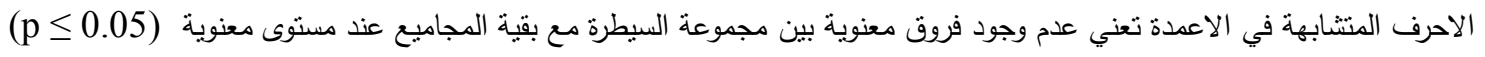

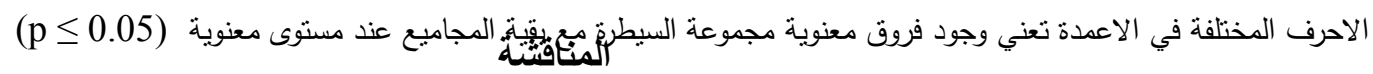

بينت المقاطع النسجية لكبد الجرذان المعاملة بالستانوزولول عند التركيز 10 ملغم/ كغم من وزن الجسم بعد أربع اسابيع من المعاملة وجود تغيرات نسجية تمثلت في التنكس الفجوي الدهني في هيولي الخلايا الكبدية وتغير دهني مع توسع الجيبانيات بنديات واحتقان الوريد المركزي. وبعد ثمانية أسابيع من المعاملة لوحظ زيادة شدة التغيرات النسجية اذ أظهرت المقاطع تغيراً دهنياً شديداً

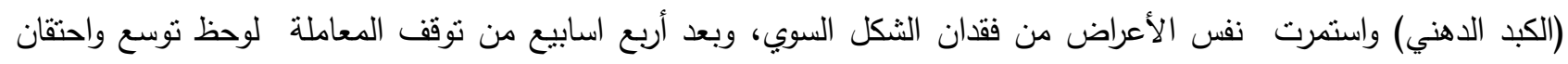

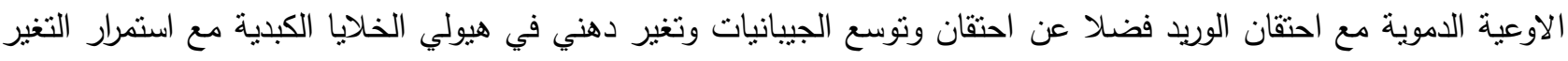

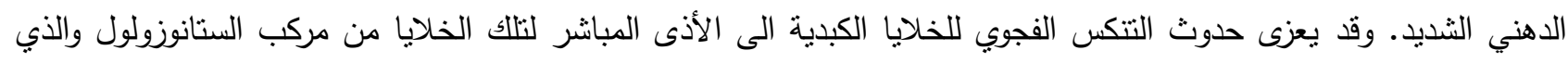
أدى إلى تحفيز الاستجابة الالتهابية وهي المسؤولة عن التغيرات المرضية المرتبطة بتحرير السوبرأوكسايد بواسطة هذه المركبات مما يسهم في أكسدة الدهون الفسفورية في غشاء الخلية الكبدية ويؤدي الى تحور كيميائي وخلا في حاجز النفوذية الاختيارية

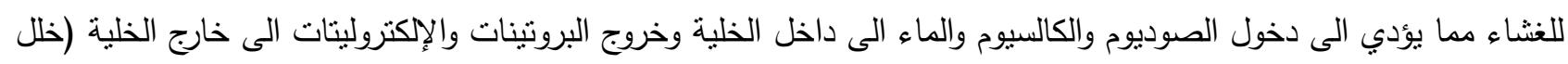

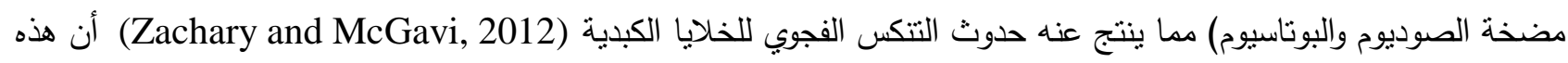
الآفات جاءت متفقة مع الباحثون (Harkin et al., 2000). في دراسة أجريت على سمية الستانوزولول في القطط حيث لاحظ

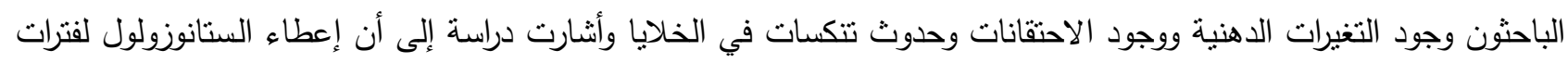
قصيرة يؤدي الى تتكس دهني وتوسع الجيبانيات و نتكس زجاجي فضلا عن ما يحدثه الستانوزولول من اذى للمايتوكوندريا مقارنة (Luis et al., 1999; Zelleroth et al., 2019)

مع مجموعة السيطرة

Boldenone undecylenate الباحثون (Tousson et al., 2011) في دراسة أجريت على أكباد الأرانب لمعرفة تأثيرات مركب

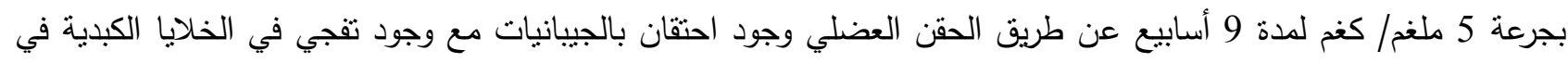
منطقة الفصيص المركزي. يعزى ظهور التغير الدهني الى استمرار الاذى بعد حدوث التورم الخلوي ونخر بعض وجن الخلايا الكبدية

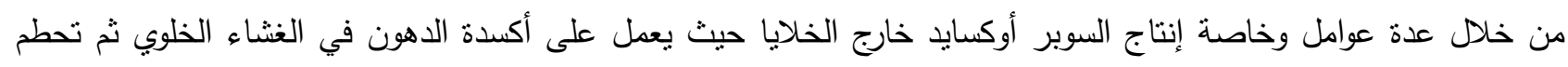
الغشاء الخلوي والثبكة البلازمية الخشنة مما يؤدي إلى قلة تصنيع الـ Apoprotein والتي تتحد مع الدهون لتكوين التهائ البروتين الدهني والتي تفرز خارج الخلية الكبدية مما يؤدي الى عدم تحرير الأحماض الدهنية وتجمعها داخل هيولي الخلية وتظهر الدهون

المتراكمة في الخلايا الكبدية نسجيا كفجوات دائرية فارغة (Zachary and McGavi, 2012).

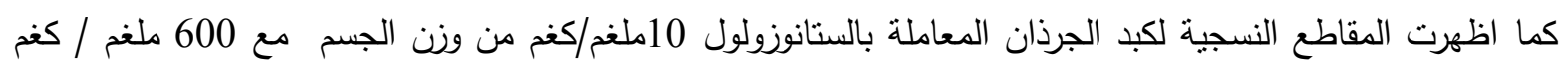
من وزن الجسم من فيتامين E عند (8,4) اسابيع من المعاملة وجود تغيرات تمثلت باختزال الفجوات الدهنية في هيولي الخلايا الكبدية اي وجود تغير دهني منتشر فضلا عن توسع الجيبانيات مع النخر التجلطي لبعض الخلايا الكبدية وبعد أربع اسابيع من فئن 
توقف المعاملة لوحظ التغير الدهني في خلايا الكبد مع توسع الجيبانيات بشكل اقل وتتكس فجوي شديد، و تثخن في جدار الوريد المركزي، مع نخر في بعض الخلايا الكبدية واختزال قطرات الدهن. وقد أظهرت دراسة على أنثى الكلب أعطيت الستانوزولول ومن ثم Silymarin بجرعة 30 ملغم /كغم وهو من مضادات الأكسدة تثبط الستانوزولول المحدث لتسمم الكبد في الكلاب حيث أدى إلى حماية أنسجة الكبد من الاجهاد التاكسدي

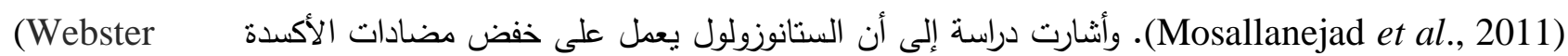
فيما يعتبر فيتامين End Cooper, 2009)

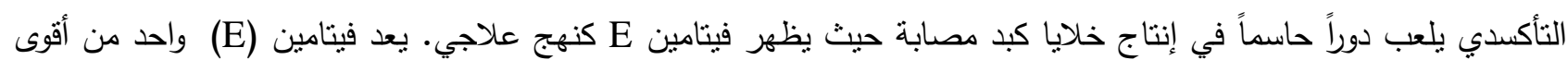
مضادات الأكسدة في الطبيعة (Peh et al., 2015). يرتبط تثبيط PKC بواسطة a-tocopherol بشكل رئيسي مع الحد من انتشار الخلايا في العديد من أنواع الخلايا المختلفة، بما في ذلك خلايا العضلات الملساء الوعائية وأحاديات الخلايا الضامة (Cook-Mills, 2013) والخلايا البلعمية والعدلات والأرومات الليفية وكذللك خطوط الخلايا السرطانية المختلفة يسبب الستانوزولول الإجهاد التأكسدي، والسموم الداخلية والكبد، والخلل الوظيفي للميتوكوندريا (Pey et al., 2003). تم استخدام

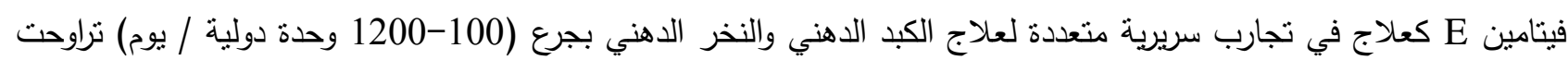
بين 6 أثهر إلى سنتين حيث لوحظ تحسن ملحوظ في الكيمباء الحيوية في الكبد والأنسجة (Lavine et al., 2011).

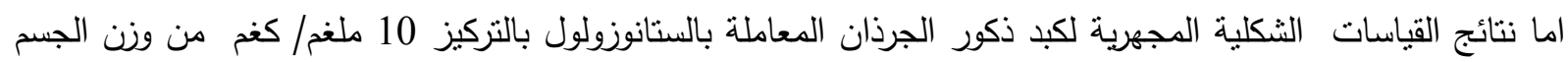
عند كافة الفترات فقد أوضحت ارتفاعاً معنوي في قطر الجيبانيات الكبدية في حين لوحظ انخفاض أقطار هذه الجيبانيات عند (Tanasov et استخدام فيتامين 600 ملغم/كغم من وزن الجسم وجاءت هذه النتائج مطابقة لما ذكره الباحث (al , 2014 والذي ذكر ان استخدام الاندروجينات البنائية يؤدي الى توسع في اقطار الجيبانيات الكبدية وهذا يؤكد ان اعطاء فيتامين E للجرذان المعاملة بالستانوزولول يؤدي إلى تحسن في التركيب النسيجي لجداران أوعيتها الدموية. كما اظهرت نتائج

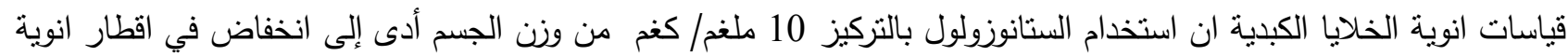

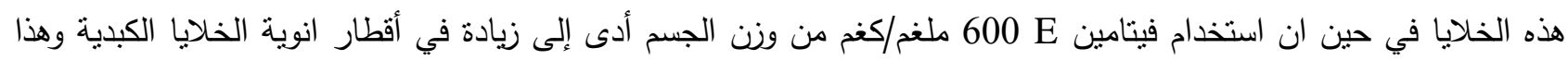

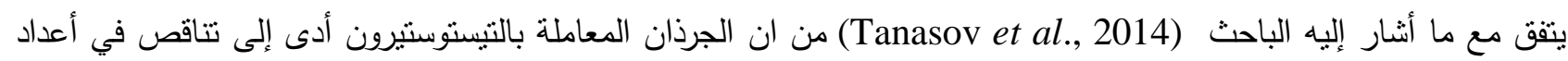
(Karina et al., الخلايا الكبدية وحجوم الانوية في حين اختلفت نتائجنا مع ما ذكره الباحث

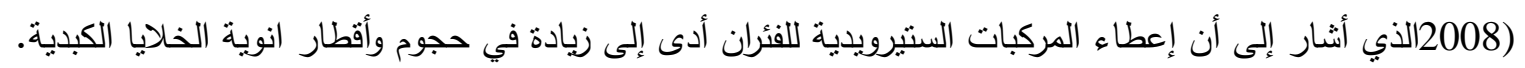
نستتنج من هذه الدراسة ان مركب الستانوزولول ممكن ان يحدث تغيرات مرضية عيانية ونسجية في الكبد تمثلت بالتنكس

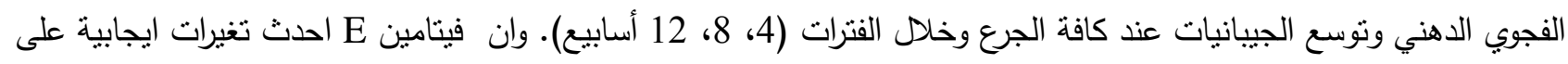
المسنوى النسجي باعتباره مضاداً للأكسدة كما احدث الستانوزولول تغيرات شكلية وقياسية في أقطار كل من جيبانيات الكبد وانوية

\section{المصادر}

Al-Kennany, E.R. (2013). "Histochemical Technique". $1^{\text {st }}$ ed., Al-Ola for Printing and Publishing. Iraq, pp. 30-50.

Balcells, G.; Matabosch, X.; Ventura, R. (2017). Detection of stanozolol O- and N- sulfate metabolites and their evaluation as additional markers in doping control. Drug Test Anal, 9,1001-1010. doi: 10.1002/dta.2107.

Buttner, A.; Thieme, D. (2010). Side effects of anabolic androgenic steroids: pathological findings and structure-activity relationships. Exp. Pharmacol., 195:459-84. doi: 10.1007/978-3540-79088-4_19 
Cook-Mills, J.M. (2013). Isoforms of Vitamin E Differentially Regulate PKC $\alpha$ and Inflammation: A Review. J. Clin. Cell. Immunol., 4:1000137. doi: 10.4172/2155-9899.1000137.

El Hadi, H.; Vettor, R.; Rossato, M. (2018). "Congenital Vitamin E deficiency" In: Preedy, V.R., Patel V.B., "Handbook of Famine, Starvation, and Nutrient Deprivation". Springer International Publishing AG; Basel. Switzerland, pp. 1-18.

Harkin, K.R.; Cowan, L.A.; Adrews, G.A.; Basavaba, R.J.; Fischer, J.R.; Debower, L.J.; Roush, J.K.; Guglielmin, M.L. ; Kirk, L.A. (2000). Hepatotoxicity of stanazolol in cats. J. Am. Vet. Med. Assoc., 217, 681-684.

Jassim, H.M.; Hassan, A.A. (2011). Changes in some blood parameters in lactating female rats and their pups exposed to lead: effects of vitamins C and E. I. J. V.Sc., 25 (1), 1-7.

Johansson, A.; Rundolfsson, S.H.; Wikstrom, P.; Bergh, A. (2004). Altered level of angioprotein 1 and Tei 2 are associated with androgen regulated vascular regression and growth in the ventral prostate in adult mice and rat. J. Endocrinol., 146, 3463-3470.

Karina, F.; Marcela, A.; Flávia, D.; Helena, C.F.; Oliveira, B.; Maria, A. (2008). Hepatocyte nuclear phenotype: the cross-talk between anabolic androgenic steroids and exercise in transgenic mice . Histopathol., 23, 1367-1377.

Lavine, J.E.; Schwimmer, J.B.; Van Natta, M.L.; Molleston, J.P.; Murray, K.F.; Rosenthal, P.; Abrams, S.H.; Scheimann, A.O.; Sanyal, A.J.; Chalasani, N. (2011). Effect of vitamin E or metformin for treatment of nonalcoholic fatty liver disease in children and adolescents: The Tonic randomized controlled trial. JAMA, 305,1659-1668. doi: 10.1001/jama.2011.520.

Luis, D.B.; Manuel, Z.; Santiago, T.; Antonio, L.; Bonifacio, N.; DõÂaz-Chico, J.J. ; Cabrera, O. P.L. (1999). Evaluation of acute and chronic hepatotoxic effects exerted by anabolicandrogenic steroid stanozolol in adult male rats. Arch. Toxicol., (1999) 73, 465-472.

Mosallanejad, B.; Avezeh, R.; Najafazadeh, H. (2011). Successful Treatment of stanozolol Induced- hepatotoxicity with silymarin in bitch. Asia. J. Anim. Sci, 5 (3), 213-218.

Nieschlag, E.; Vorona, E. (2015). Doping with anabolic androgenic steroids (AAS): Adverse effects on non-reproductive organs and functions. Rev. Endocr Metab Disord., 16(3),199211. doi: 10.1007/s11154-015-9320-5

Peh, H.Y.; Tan, W.S.; Liao W.; Wong, W.S. (2015). Vitamin E therapy beyond cancer: Tocopherol versus tocotrienol. Pharmacol. Ther., 162,152-69.doi:10.1016/j.pharmthera.2015.12.003.

Petrie, A.; Watson, P. (1999). "Statistics for Veterinary and Animal Science". Blackwell publishing Co., Oxford, pp. 95-99.

Pey, A.; Saborido, A.; Blazquez, I.; Delgado, J.; Megias, A. (2003). Effects of prolonged stanozolol treatment on antioxidant enzymes activities, oxidative stress markers, and heat shock protein HSP72 levels in rat liver. J. Steroid. Biochem. Mol. Biol., 87, 269-77.

Tanasov, V.S.; Neto, W.K.; Leandro Gonçalves, L.; Beatriz, L.; Maifrino, M.; Sousa, R.R.; Gama, E.F. (2014). Use of Anabolic Steroid Altered the Liver Morphology of Rats El Uso de Esteroides Anabólicos Altera la Morfología del Hígado de Ratas. Int. J. Morphol., 32(3),756-760.

Tousson, E.; Allu-Eldeen, A.; El-Moghazy, M. (2011). P53 and BC1-1 expression in response to boldenon induced liver cells injury. Toxicol. Ind. Health., 27, 711-718.

Vieira, T.M.; Rossi, W.C.; Da-Ré, G.F.; Damião, B.; Marques, P.P. Esteves, A. (2019). Effect of testosterone cypionate and stanozolol on the heart of young trained mice: A morphometric study. J. Steroids., 145,19-22.

Webster, C.R.; Cooper, J. (2009). Therapeutic use of cytoprotective agents in canine and feline hepatobiliary disease. Vet. Clin. North Am. Small Anim. Pract., 39, 631-652.

Zachary, J.F.; McGavin, M.D. (2012). " Pathologic Basis of Veterinary Disease". $5^{\text {th }}$ ed.. Elsevier Mosby Inc. USA. 
Zelleroth, S.; Nylander, E.; Nyberg, F.; Grönbladh, A. Hallberg, M. (2019). Toxic Impact of Anabolic Androgenic Steroids in Primary Rat Cortical Cell Cultures. J. Neuroscience., 15(397), 172-183. 